
15 8

\title{
A comparison of heat wave climatologies and trends in China based on multiple definitions
}

1. Key Laboratory of Meteorological Disaster, Ministry of Education (KLME)/ Joint International Research Laboratory of Climate and Environmental Change (ILCEC)/ Collaborative Innovation Center on Forecast and Evaluation of Meteorological Disasters (CIC-FEMD)/ Earth System Modeling Center, Nanjing University of Information Science and Technology (NUIST), Nanjing, 210044, 1 China;

2. State Key Laboratory of Cryospheric Science, Chinese Academy of Sciences, Lanzhou 730000, China

3. Department of Geography, University of Portsmouth, U.K.

* Corresponding author E-mail address: yqingl@ 126.com

(1)

\footnotetext{
* Corresponding author E-mail address: yqingl@ 126.com
} 
Abstract:

Heat waves (HWs) can have disastrous impacts on human activities and natural systems, and are one of the current foci of scientific research, particularly in the context of global warming. However, there is no standard definition of a HW, which makes assessment of temporal trends a challenge. In this study, based on daily mean, maximum and minimum temperature, and relative humidity datasets from China Meteorological Administration, the patterns, trends and variations of HW in China during 1961-2014 are investigated. Sixteen previously published HW indices (HIs) are calculated, which are divided into two types using relative and absolute threshold temperatures, respectively. During 1961-2014, both relative and absolute threshold HIs show the highest number of HW in Jianghua and South China, geographically consistent with the climate characteristics of China. The majority of HIs shows negative/positive trends of HW days before/after 1990 over the whole of China, but especially in Jianghua and South China. This reflects rapid warming since 1990. There are significant correlations among different HIs in the same type (both absolute and relative), but correlations are weak between relative and absolute threshold HIs. Because relative and absolute HIs show contrasting trends, the choice of $\mathrm{HI}$ is therefore critical for future analysis.

Key words: China; heat wave; multiple heat wave indices; 


\section{Introduction}

According to the Fifth Assessment Report of the Intergovernmental Panel on Climate Change (IPCC AR5), global mean surface temperature has increased with a rate of 0.85 (0.65 to 1.06) ${ }^{\circ} \mathrm{C} /$ decade during 1880 to 2012 (IPCC, 2013), and each of the last three decades has been successively warmer at the Earth's surface than any preceding decade (IPCC, 2013). Warming leads to an increase in heat wave (HW) occurrence in terms of magnitude, frequency and duration (Meehl and Tebaldi, 2004), and it is likely that the frequency of HWs has increased in large parts of Europe, Asia and Australia (IPCC, 2013). Previous studies have shown that HWs have great social and environmental impacts (Anderson and Bell, 2011; Habeeb et al., 2015; Perkins, 2016; Wang et al., 2015). For example, HWs are associated with increased levels of human morbidity and mortality (Anderson and Bell, 2011; Meehl and Tebaldi, 2004; Tan et al., 2007), and influence ecosystems, agriculture production and forest fire frequency etc. (Unal et al., 2013). Thus there have been frequent studies of HW changes (Smith et al., 2013; Tan et al., 2007; Z Wu et al., 2012b).

Although there is no universally accepted definition of a HW, there are numerous studies analyzing the patterns, trends, and occurrences of HWs on regional and global scales, especially in heavily populated regions. Studies include those in Europe (Carril et al., 2007; Della-Marta et al., 2007; Fischer and Schär, 2010; Kyselý, 2010; Pongrácz et al., 2013; Tomczyk and Bednorz, 2016), North America (Bumbaco et al., 2013; Z Wu et al., 2012b), central and southern Africa (Lyon, 2009), China (Sun et al., 2014; Z Wu et al., 2012a), and Australia (Cowan et al., 2014; Lewis and Karoly, 2013; Tryhorn and Risbey, 2006). The synoptic causes of HWs are also examined by many researchers, including the 2003 European HW (Schär et al., 2004), the exceptionally warm 
summer of 2010 in eastern Europe and large parts of Russia (Barriopedro et al., 2011; Trenberth and Fasullo, 2012), and that in eastern China in the summer of 2013 (Sun et al., 2014). Both the 2003 European and 2010 Russian HW broke numerous temperature records, and are considered mega-HWs, due to their unprecedented magnitude (Fischer, 2014; Perkins, 2016). Thus, the topic has received worldwide attention in recent decades.

As HWs have considerable impact on natural processes and human activities, any increasing trends would have important consequences for environmental policy and management (Barriopedro et al., 2011; Meehl and Tebaldi, 2004; Perkins, 2016; Schär et al., 2004). In recent decades, China has been one of the countries, arguably most influenced by climate change due to its pronounced monsoonal characteristics, with marked increases in extremes of temperature being observed (Qian and Lin, 2004; Ren et al., 2011; Wang et al., 2015; You et al., 2011). Recent studies (Chen et al., 2013; Sun et al., 2014; Z Wu et al., 2012a) have pointed out that reduced snow cover in the western Tibetan Plateau and associated high pressure over Mongolia could encourage the occurrence of HWs in northern China on the one hand, while the anthropogenic influence has increased the likelihood of extreme 2013 summer HW in eastern China on the other. However, few studies have investigated the characteristics of HW occurrence at a nationwide scale in China over a longer period. The objective of this study therefore is to analyze the climatological patterns and trends of HWs in China during 1961-2014 from multiple indices used in previous studies (Fischer and Schär, 2010; Robinson, 2001; Smith et al., 2013). To investigate the spatial variability of HWs in China, the frequency, duration, and intensity of HWs in sub-regions in China are all examined. 


\section{Dataset and method}

\subsection{Homogenized temperature dataset}

Daily maximum temperature (Tmax), mean temperature (Tmean), minimum temperature (Tmin) and relative humidity (RH) from 574 stations in China (Figure 1) for 1961-2014 are obtained from National Meteorological Information Center, China Meteorological Administration. Daily temperatures have been adjusted for homogeneity and abrupt discontinuities have been corrected (Li and Dong, 2009; Li et al., 2004). Among the 574 stations, most have very small amounts of missing data (Figure 2). For example, 11\%, $17.9 \%$ and $17.1 \%$ of stations for Tmean, Tmax and Tmin respectively only have 1 missing day in the 54-year period, and it is rare for there to be more than 10 missing days in total. In view of the fact that missing data can constrain most HW definitions, missing values less than 3 days duration are interpolated with the average of the values at day -1 and day +1 , while missing values over periods longer than 3 days are interpolated with the long-term average over 54 years. The dataset continually updates in real time and is frequently used in climate change assessments ( $L i$ et al., 2014; $J$ Wu and Gao, 2013). Eight sub-regions of China are defined using the boundaries shown in Figure 1.

\subsection{Multiple definitions of heat wave}

There is no consensus on the definition of a HW at present (Perkins and Alexander, 2013; Robinson, 2001). Because HW definitions differ in past studies, this can make it challenging to compare results. It is important to make clear whether patterns and trends reported by one definition are comparable with those obtained using other definitions. Climate change and its impacts is only fully evaluated by comparing many different definitions. Thus sixteen HW indices (HIs) are used in our study shown in Table 2, with twelve of them used by Smith et al. (2013). The 
111 HIs can be categorized into relative and absolute threshold types.

112

113

\subsubsection{Relative thresholds}

The relative threshold types (HI1 through HI9) of HW are characterized by a certain number of consecutive days above a fixed percentile of the temperature distribution during the warm season May to September (defined over 1961-1990). Generally, these definitions differ in (1) the metric used e.g., Tmean (HI1-2), Tmin (HI3), Tmax (HI4-7) and apparent temperature (AT, HI8-9), (2) which percentile is used, e.g., $95^{\text {th }}$ in HI1, and (3) the consecutiveness constraint applied, e.g., two days in HI1.

Indices HI01-04 are drawn from Anderson and Bell (2011) and were used for the analysis of mortality risk during HW days compared with non-HW days. HI05 was used by Meehl and Tebaldi (2004) to detect extreme HW in the $21^{\text {st }}$ century. Similarly, HI06 was used by Fischer and Schär (2010) to assess the future changes of HW in Europe. HI07, developed based on a significant increase in mortality, was used by Ye et al. (2013) to detect the spatio-temporal characteristics of HWs in China. AT are used in HI8 and HI9 from Steadman (1984), defined as at least 1 day with AT exceeding the $90^{\text {th }}$ and $95^{\text {th }}$ percentile, respectively. AT represents heat stress on the human body by accounting for the additional effects of relative humidity and incorporates the nonlinear nature of heat stress.

\subsubsection{Absolute thresholds}

The absolute threshold types (HI10 through HI18) indicate days exceeding fixed absolute values of temperature. Similarly, these definitions differ in (1) the metric used, e.g., Tmax (HI10-12) or HImax (HI13-16), (2) the magnitude of threshold, e.g., $35^{\circ} \mathrm{C}$ in HI10, and (3) the consecutiveness constraint applied, e.g., 3 days in $\mathrm{HI} 10.35^{\circ} \mathrm{C}$ is used in $\mathrm{HI} 10$ as the threshold that corresponds to 
issued Chinese Meteorological Administration heat warnings. HI11 is similar to HI10 but with $32{ }^{\circ} \mathrm{C}$ as the threshold. HI12 considers the combined effects of daily maximum and minimum temperature, which is able to detect whether daytime heat can be relieved through nighttime (minimum) temperature. HI13 through HI16 follow the procedures of Steadman (1979), using the National Weather Service's (NWS) heat index $\left(\mathrm{I}_{\mathrm{NWS}}\right) . \mathrm{I}_{\mathrm{NWS}}$ in ${ }^{\circ} \mathrm{F}$ is calculated using temperature and relative humidity. Other factors such as vapor pressure, wind speed and, characteristics of human activity levels, sweating rate etc. were used in the original study to parameterize the equation (Smith et al., 2013). The daily maximum heat index is classified into one of four categories: 1) Caution: $>80{ }^{\circ} \mathrm{F}$ (HI13), 2) Extreme Caution: $>90{ }^{\circ} \mathrm{F}$ (HI14), 3) Danger: $>105{ }^{\circ} \mathrm{F}$ (HI15), and 4) Extreme Danger: >130 F (HI16) (Smith et al., 2013; Steadman, 1979).

\subsection{Trend calculation}

The Mann-Kendall (MK) test for trends and Sen's slope estimates (Sen, 1968), are widely used to compute trends in hydrological and meteorological series (Joshi and Pandey, 2011; You et al., 2015). However, the persistence in hydrological and meteorological time-series can contaminate the raw MK test results, so in this study we use the modified MK (MMK) (Hamed and Rao, 1998) which considers the lag-1 autocorrelation (Hamed and Rao, 1998; Q Zhang et al., 2011). A trend is considered to be statistically significant if it is significant at the $5 \%$ level.

\section{Results}

Figure 3 shows the average (left panel), standard deviation (middle panel) and 95th percentile (right panel) of five temperature metrics based on the climatological reference period 1961-1990: Tmean, Tmax, Tmin, AT $\left({ }^{\circ} \mathrm{C}\right)$ and $\mathrm{I}_{\mathrm{Nws}}\left({ }^{\circ} \mathrm{F}\right)$. The five temperature metrics have similar 
climatological patterns with higher values in eastern China and lower values in the west. This pattern provides the climate background to define relative HIs. Figure 4 presents the correlation coefficients between several statistics of these five temperature metrics and station elevation. For the climatologies, a significant negative relationship can be seen (left panel) because the temperature tends to decrease with increasing altitude. However, there is an unusual increase of AT and $\mathrm{I}_{\mathrm{NWs}}$ within the 4000-4500 m elevation range. The standard deviation of the five metrics also tends to decrease with elevation for Tmax, Tmean, and Tmin, suggesting that variability of temperature is reduced at high elevations. However, prominent negative correlations with elevation are still detected for the standard deviation of AT and $\mathrm{I}_{\mathrm{NwS}}$. The results using the 95th percentile of temperature metrics are similar to those using the average.

Figure 5 shows the annual average of HW days in China defined using the 16 HIs during 1961-2014. The scale bars vary depending on the definition so as to accentuate the spatial patterns. The average number of annual HW days over eight sub-regions in China during 1961-2014 is summarized in Table 2.

Using different definitions, the annual average number of HW days during 1961-2014 varies from 0.56 (HI7) to 90.35 (HI13). Three HIs have annual averages below 3 days (HI7, HI12 and HI16), and six have annual averages above 10 days (HI1, HI8, HI11, HI13, HI14 and HI15).

Despite large differences in absolute frequencies, the spatial patterns for most HIs are broadly similar. The highest frequency of HW occurrence is usually in either the JH or SC sub-region (for sub-region definition see Figure 1). For instance, four HIs (HI5-HI7, and HI10) have the largest frequency in the JH sub-region, and eight HIs (HI3-HI4, and HI11-HI16) in the SC sub-region. The NEC and TP sub-regions experience the lowest frequencies in most HIs. On the other hand, 
HI8-HI9 show the largest annual average of HW days in the WNC region, and HI1-HI2 in the TP region. This suggests that not all HIs agree and potentially identify contrasting characteristics of HW occurrence in China.

Figure 6 shows the time series of average HW days (upper panels) and $\mathrm{Z}$ values with modified MK trend test (lower panel) over the whole of China during 1961-2014 for each HI. It is clear that most time series show decreased trends before 1990s and rapid increases afterwards, leading to positive trends overall during 1961-2014. Figure 7 summaries trend magnitudes and significance for all HIs in all sub-regions during 1961-2014, 1961-1990 and 1991-2014, respectively. The spatial patterns of these trends during the same three periods are presented in Figures 8, 9 and 10, respectively.

The general findings from Figure 7 are that most HIs show an increase over the whole period (first of the three columns in each case), but sometimes there is a significant decrease during 1961-1990 followed by a rapid increase during 1991-2014. Although there are exceptions to these generalizations, the absolute indices (H10-H16) often show strong decreases in the first half of the record and the most statistically significant increases tend to be in the relative indices (H01-H09) in JH, SC and SWC, especially over recent decades.

Examining the whole period (1961-2014), the majority of 16 HIs shows significant warming in each region, except HI16 (Figure 8). The first four HIs show strong increases over most of China, particularly HI1 and HI3. The strongest trends are in the southern regions. Unusually, the NC region has experienced a significant decreasing trend for some indices (HI10 and HI16) and decreasing trends also occur in JH and TP regions for HI8 and HI9. Although relatively small areas, these do cover large centers of population, and so we cannot assume that HWs are 
increasing in frequency everywhere in China, even over the longest period. Moreover, it is notable that five (NC, JH, SC, TP, WNW) of eight regions all experience a significant decreasing trend for HI16 that may be related to a decreasing trend of relative humidity in China over recent decades.

Over the period 1961-1990 (Figure 9), decreasing trends are dominant and have been found for all HIs in NC, JH and ENC regions. The strongest decreases are usually reported in the $\mathrm{JH}$ region. There are exceptions to the general pattern with an increasing trend detected for eleven HIs in WNW, four in NEC, seven in SC, three in SWC and six in the TP region (also see Figure 7).

During the most recent period (1991-2014) there has been a strong turnaround in HW days with strong increases in all regions and for all HIs (Figure 10). Particularly rapid increases were detected in JH for HI1, HI3, and HI11; SC for HI1, HI2, HI3 and HI11; and SWC for HI1-HI4. Decreasing trends were only detected for HI8 in NC and WNC; HI9 in WNC and ENC; HI15 in NC, TP, WNW and ENC; and HI16 in NC and ENC. To summarize, both relative and absolute HIs show decreasing trends up until 1990 (particularly in the JH region) but there has been a strong reversal since 1990. Although the contrasting trends could weaken the longer-term trends during 1961-2014 to some extent, nevertheless there are still significant increases over the longer-term period in the majority of regions.

Table 3 summarizes the correlation coefficients between the annual HW days calculated for each HI. It is clear that correlations among HIs in the same type are strongly positive, but those between HIs in the two different types (absolute vs relative) are weak and even negative in some cases. Moreover, spatial patterns and trends observed in relative threshold HIs (HI1-HI9) are not always consistent with absolute threshold HIs (HI10-HI16). This means the selection of HI has important consequences. The two types of HI show different impacts and significant differences 
exist, evident in contrasting trends of duration, intensity and frequency of HW events. Relative thresholds are commonly used to detect the evolving statistics of extremes using a probability of exceedance in some metric and a fixed percentile of the temperature distribution (Smith et al., 2013). On the other hand, absolute thresholds encompass more absolute or fixed aspects of human physiology, acknowledging that many thermo-physiological functions are fundamentally the same among all populations. Common heat alerts are based on absolute thresholds (Amengual et al., 2014; Smith et al., 2013).

\section{Discussion and conclusions}

HWs are of great environmental concern for numerous reasons, including their influence on local drought and desertification (Meehl and Tebaldi, 2004; Schär et al., 2004; Z Wu et al., 2012a) which can lead to water shortages and a worsening ecological environment. Therefore, the understanding of HWs trends in China is essential to understand why there are discrepancies between HW definitions for climate scientists, health researchers, and the general public. We compare results based on multiple definitions (Meehl and Tebaldi, 2004; Perkins, 2016; Smith et al., 2013; Z Wu et al., 2012b) in this study.

In this study, sixteen HIs have been compared and results are generally consistent with warming observed in previous studies (Qian and Lin, 2004; Ren et al., 2011; Sun et al., 2014; You et al., 2011). During 1961-2014, the frequency of HW days has increased over nearly all of China, and the majority of HIs show similar patterns. The largest positive trends have occurred in JH, SC and SWC regions where there are large population centers and already high levels of heat stress. Because of varying definitions of HWs, the geographical patterns of HW days are varied among 
the HIs. Usually there are higher values located in the south of China and lower values in the north, but this pattern is strongest for the absolute indices (H10-H16). The relative indices can show contrasting spatial distributions. In addition, HI8 and HI9 are calculated from apparent temperature which includes both temperature and relative humidity, and the geographical patterns of high HW days from both these indices correspond with high humidity (i.e. focused in the east of China). Similar research in the United States (Smith et al., 2013) has shown that the spatial range in average number of HW days is greater for absolute than for relative HIs which is also shown in our study (note the particularly high ranges for HI13 and HI15).

From the trend analysis, it is apparent that most HIs decrease up until 1990 and increase afterwards, which is in line with the rapid warming after the 1990s in China (Li et al., 2014; Qian and Lin, 2004; Ren et al., 2011). Over the longer 1961-2014 period, the JH and SC regions have experienced both the largest magnitude and most widespread increases in HWs in most HIs. In a previous study, Wu et al. (2012) applied HI06 to northern China, and showed increased HW days in recent decades, connected with variability in the western Tibetan Plateau snow cover. Wang et al. (2015) defined a hot spell as a day with Tmax higher than the 95th percentile threshold of Tmax during 1961-1990 (not one of the HIs used in this paper), and studied the changes of hot spells during 1960-2005 from both observations and CMIP5 model output. In another study, which used HI11, intensified HWs were shown to occur in eastern China associated with changes in large scale circulation. In many cases an abnormally intense summer subtropical high developed over eastern China, is connected to a west-drifted west Pacific subtropical high and a weakened India-Burma trough (Tan and Huang, 2004; Tan et al., 2007; Ye et al., 2013). Beyond these case-study examples, it is difficult to compare studies, because differences in the period of 
analysis, data sources, the number of stations, and HWs definitions can all contribute to inconsistencies in results (Smith et al., 2013). Unfortunately, this can lead confusion in assessments of the magnitude and geography of HW trends.

Since there is no standard definition for a HW (Table 4), we have applied analysis of observations in China to compare patterns and trends across sixteen previously published HIs. The choice of HIs has been shown to be critically important to the resulting analysis of patterns and trends (Figure 9). In future work similar index comparisons could be translated easily to different datasets, in particular if a focused local analysis is required. Similar comparisons should therefore be performed using other meteorological datasets and for future climate model projections in order to explore the full range of potential HW impacts associated with climate variability and change (Fischer, 2014; Fischer and Schär, 2010; Meehl and Tebaldi, 2004; Smith et al., 2013).

The temporal evolution of different HIs appears to be reasonably coherent, and efforts should be made to obtain a clearer understanding of the underlying physical mechanisms which explain HW occurrence. The scientific understanding of HWs has been summarized into three main drivers: synoptic systems, soil moisture and land surface interactions, and climate variability (Perkins, 2016). In China, it is mentioned that circulation anomalies are a key factor behind extreme HWs ( $\mathrm{Lu}$ and Chen, 2016). Synoptic-scale characteristics and associated atmospheric circulation anomalies within extreme HWs in southeastern, southwestern, and eastern China are investigated by (Wang et al., 2016). These are the regions where the highest frequencies of HWs are also detected among most HIs in this study. During the studied period, the sixteen HIs have negative correlations with Pacific Decadal Oscillation (PDO) index in most cases (Table 5). From 1960 to 1990, the PDO was in a positive phase, which will weaken the East Asian summer monsoon, and 
decrease the frequency of extreme high temperature events in China. Thus it is suggested that the PDO may contribute to the variability of HWs in China. In addition, many studies have also pointed out that Western North Pacific Subtropical High and the South Asian High, as the major components of the East Asian Monsoon system, play an important role in the variability of high temperatures in China (Wang et al., 2014; P Zhang et al., 2005). Thus, synoptic systems and circulation anomalies associated with extreme HWs in China are a focus of ongoing study, necessary for a deeper understanding of HWs in China.

Acknowledgments. This study is supported by the State Key Program of National Natural Science Foundation of China (41230528), Jiangsu Specially-Appointed Professor project and Jiangsu Natural Science Funds for Distinguished Young Scholar "BK20140047”, Six talent peaks project in Jiangsu Province (2015-JY-010); Opening Fund of Key Laboratory of Land Surface Process and Climate Change in Cold and Arid Regions, CAS) (LPCC201512). This study is also funded by "the Priority Academic Program Development of Jiangsu Higher Education Institutions" (PAPD).

\section{References}

Amengual, A., V. Homar, R. Romero, H. Brooks, C. Ramis, M. Gordaliza, and S. Alonso (2014), Projections of heat waves with high impact on human health in Europe, Global and Planetary Change, 119, 71-84.

Anderson, G., and M. L. Bell (2011), Heat waves in the United States: mortality risk during heat waves and effect modification by heat wave characteristics in 43 U.S. communities, Environmental health perspectives, 119(2), 210-218.

Barriopedro, D., E. M. Fischer, J. Luterbacher, R. M. Trigo, and R. García-Herrera (2011), The hot summer of 2010: redrawing the temperature record map of Europe, Science, 332(6026), 220-224. 

doi:10.1175/jamc-d-12-094.1.

314 Carril, A. F., S. Gualdi, A. Cherchi, and A. Navarra (2007), Heatwaves in Europe: areas of homogeneous variability and links with the regional to large-scale atmospheric and SSTs anomalies, Climate Dynamics, 30(1), 77-98, doi:10.1007/s00382-007-0274-5.

Chen, M., F. H. Geng, L. M. Ma, and W. D. Zhou (2013), Analyses on the heat wave events in Shanghai in Recent 138 years, Plateau Meteorology (in Chinese), 32(2), 597-607. Longer, and Hotter Heat Waves for Australia in the Twenty-First Century, Journal of Climate, 27(15), 5851-5871, doi:10.1175/JCLI-D-14-00092.1.

Della-Marta, P. M., J. Luterbacher, H. Weissenfluh, E. Xoplaki, M. Brunet, and H. Wanner (2007), Summer heat waves over western Europe 1880-2003, their relationship to large-scale forcings and predictability, Climate Dynamics, 29(2), 251-275, doi:10.1007/s00382-007-0233-1. European heatwaves, Nature Geoscience, 3(6), 398-403. Hazards, 76(3), 1651-1665, doi:10.1007/s11069-014-1563-z.

Hamed, K. H., and A. R. Rao (1998), A modified Mann-Kendall trend test for autocorrelated data, Journal of Hydrology, 204, 182-196.

IPCC (2013), Summary for Policymakers of Climate change 2013: The Physical Science Basis. Contribution of Working Group I to the Fifth Assessment Report of the Intergovernmental Panel on Climate Change Cambridge, UK: Cambridge University Press. Joshi, M. K., and A. C. Pandey (2011), Trend and spectral analysis of rainfall over India, Journal of Geophysical Research-Atmospheres, 116, D06104.

Kyselý, J. (2010), Recent severe heat waves in central Europe: how to view them in a long-term prospect?, International Journal of Climatology, 30(1), 89-109, doi:10.1002/joc.1874. temperatures of 2013, Geophys. Res. Lett., 40(14), 3705-3709, doi:10.1002/grl.50673. 
Li, Q. X., and W. J. Dong (2009), Detection and Adjustment of Undocumented Discontinuities in Chinese Temperature Series Using a Composite Approach, Adv. Atmos. Sci., 26(1), 143-153, doi:10.1007/s00376-009-0143-8.

344 Li, Q. X., J. Huang, Z. Jiang, L. Zhou, P. Chu, and K. Hu (2014), Detection of urbanization signals in extreme winter minimum temperature changes over Northern China, Climatic Change, 122(4), 595-608, doi:10.1007/s10584-013-1013-z.

Li, Q. X., X. N. Liu, H. Z. Zhang, T. C. Peterson, and D. R. Easterling (2004), Detecting and adjusting temporal inhomogeneity in Chinese mean surface air temperature data, Adv. Atmos. Sci., 21(2), 260-268.

Lu, R.-Y., and R.-D. Chen (2016), A review of recent studies on extreme heat in China, Atmospheric and Oceanic Science Letters, 9(2), 114-121.

Lyon, B. (2009), Southern Africa Summer Drought and Heat Waves: Observations and Coupled Model Behavior, Journal of Climate, 22(22), 6033-6046, doi:10.1175/2009jcli3101.1.

Meehl, G. A., and C. Tebaldi (2004), More intense, more frequent, and longer lasting heat waves in the 21st century, Science, 305(5686), 994-997.

Nakano, M., M. Matsueda, and M. Sugi (2013), Future projections of heat waves around Japan simulated by CMIP3 and high - resolution Meteorological Research Institute atmospheric climate models, Journal of Geophysical Research: Atmospheres, 118(8), 3097-3109.

Peng, R. D., J. Bobb, C. Tebaldi, L. McDaniel, M. L. Bell, and F. Dominici (2011), Toward a quantitative estimate of future heat wave mortality under global climate change, Environmental health perspectives, 119, 701-706.

Perkins, S. E. (2016), A review on the scientific understanding of heatwaves - Their measurement, driving mechanisms, and changes at the global scale, Atmospheric Research, 164-165, 242-267.

Perkins, S. E., and L. V. Alexander (2013), On the Measurement of Heat Waves, Journal of Climate, 26(13), 4500-4517, doi:10.1175/JCLI-D-12-00383.1.

Pezza, A. B., P. van Rensch, and W. Cai (2012), Severe heat waves in Southern Australia: synoptic climatology and large scale connections, Climate Dynamics, 38(1-2), 209-224, doi:10.1007/s00382-011-1016-2. heat waves in Hungary, Advances in Geosciences, 35(35), 115-122. 
Qian, W. H., and X. Lin (2004), Regional trends in recent temperature indices in China, Climate Research, 27(2), 119-134.

373 Ren, G. Y., Z. Y. Guan, X. M. Shao, and D. Y. Gong (2011), Changes in climatic extremes over mainland China, Climate Research, 50, 105-111.

375 Robinson, P. J. (2001), On the definition of a heat wave, Journal of Applied Meteorology, 40(4), $762-775$.

Schär, C., P. L. Vidale, D. Lüthi, C. Frei, C. Häberli, M. A. Liniger, and C. Appenzeller (2004),

The role of increasing temperature variability in European summer heatwaves, Nature, 427(6972), 332-336.

Schoetter, R., J. Cattiaux, and H. Douville (2015), Changes of western European heat wave characteristics projected by the CMIP5 ensemble, Climate Dynamics, 45(5), 1601-1616.

Sen, P. K. (1968), Estimates of regression coefficient based on Kendall's tau, Journal of the American Statistical Association, 63, 1379-1389.

Shevchenko, O., H. Lee, S. Snizhko, and H. Mayer (2014), Long - term analysis of heat waves in Ukraine, International Journal of Climatology, 34(5), 1642-1650.

Smith, T. T., B. F. Zaitchik, and J. M. Gohlke (2013), Heat waves in the United States: definitions, patterns and trends, Climatic change, 118(3-4), 811-825.

Steadman, R. G. (1979), Assessment of sultriness. Part II: Effects of wind, extra radiation and barometric pressure on apparent temperature., Journal of Applied Meteorology, 18, 874-885. 193-200. Applied Meteorology, 23(12), 1674-1687.

Sun, Y., X. Zhang, F. W. Zwiers, L. Song, H. Wan, T. Hu, H. Yin, and G. Ren (2014), Rapid increase in the risk of extreme summer heat in Eastern China, Nature Clim. Change, 4, 1082 1085, doi:10.1038/nclimate2410.

Tan, J. G., and J. Huang, X. (2004), The impacts of heat waves on human health and its research method, Advances in Climate Change Research (in Chinese), 4, 680-686.

Tan, J. G., Y. Zheng, G. Song, L. S. Kalkstein, A. J. Kalkstein, and X. Tang (2007), Heat wave impacts on mortality in Shanghai, 1998 and 2003, International Journal of Biometeorology, 51(3),

Tomczyk, A. M., and E. Bednorz (2016), Heat waves in Central Europe and their circulation 
conditions, International Journal of Climatology, in press, doi:10.1002/joc.4381.

Trenberth, K. E., and J. T. Fasullo (2012), Climate extremes and climate change: The Russian heat wave and other climate extremes of 2010, Journal of Geophysical Research-Atmospheres, 117, D17103, doi:10.1029/2012jd018020.

Tryhorn, L., and J. Risbey (2006), On the distribution of heatwaves over the Australian region, Australian meteorological magazine, 55, 169-182.

Unal, Y. S., E. Tan, and S. S. Mentes (2013), Summer heat waves over western Turkey between 1965 and 2006, Theoretical and Applied Climatology, 112(1-2), 339-350.

Wang, W., W. Zhou, and D. Chen (2014), Summer High Temperature Extremes in Southeast China: Bonding with the El Niño-Southern Oscillation and East Asian Summer Monsoon Coupled System, Journal of Climate, 27(11), 4122-4138, doi:doi:10.1175/JCLI-D-13-00545.1.

Wang, W., W. Zhou, X. Li, X. Wang, and D. Wang (2016), Synoptic-scale characteristics and atmospheric controls of summer heat waves in China, Climate Dynamics, 46(9), 2923-2941, doi:10.1007/s00382-015-2741-8.

Wang, W., W. Zhou, Y. Li, X. Wang, and D. X. Wang (2015), Statistical modeling and CMIP5 simulations of hot spell changes in China, Climate Dynamics, 44, 2859-2872.

Wu, J., and X. J. Gao (2013), A gridded daily observation dataset over China region and comparison with the other datasets, Chinese Journal of Geophysics, 56(4), 1102-1111.

Wu, Z., Z. Jiang, J. Li, S. Zhong, and L. Wang (2012a), Possible association of the western Tibetan Plateau snow cover with the decadal to interdecadal variations of northern China heatwave frequency, Climate Dynamics, 39(9-10), 2393-2402, doi:10.1007/s00382-012-1439-4.

Wu, Z., H. Lin, J. Li, Z. Jiang, and T. Ma (2012b), Heat wave frequency variability over North America: Two distinct leading modes, Journal of Geophysical Research: Atmospheres, 117(D2), D02102.

Ye, D., J. Yin, Z. Chen, Y. Zheng, and R. Wu (2013), Spatiotemporal Change Characteristics of Summer Heatwaves in China in 1961-2010, Advances in Climate Change Research (in Chinese), $9(1), 15-20$.

You, Q. L., S. C. Kang, E. Aguilar, N. Pepin, W. A. Flugel, and Y. P. Yan (2011), Changes in daily climate extremes in China and their connection to the large scale atmospheric circulation during 1961-2003, Climate Dynamics, 36, 2399-2417. 
431 You, Q. L., J. Min, W. Zhang, N. Pepin, and S. Kang (2015), Comparison of multiple datasets with 432 gridded precipitation observations over the Tibetan Plateau, Climate Dynamics, 45, 791-806.

433 Zhang, P., S. Yang, and V. E. Kousky (2005), South Asian high and Asian-Pacific-American 434 climate teleconnection, Adv. Atmos. Sci., 22(6), 915-923.

435 Zhang, Q., V. P. Singh, J. F. Li, and X. H. Chen (2011), Analysis of the periods of maximum 436 consecutive wet days in China, Journal of Geophysical Research: Atmospheres, 116, D23106.

437

438

439

440

441

442

443

444

445

446

447

448

449

450

451

452

453

454 


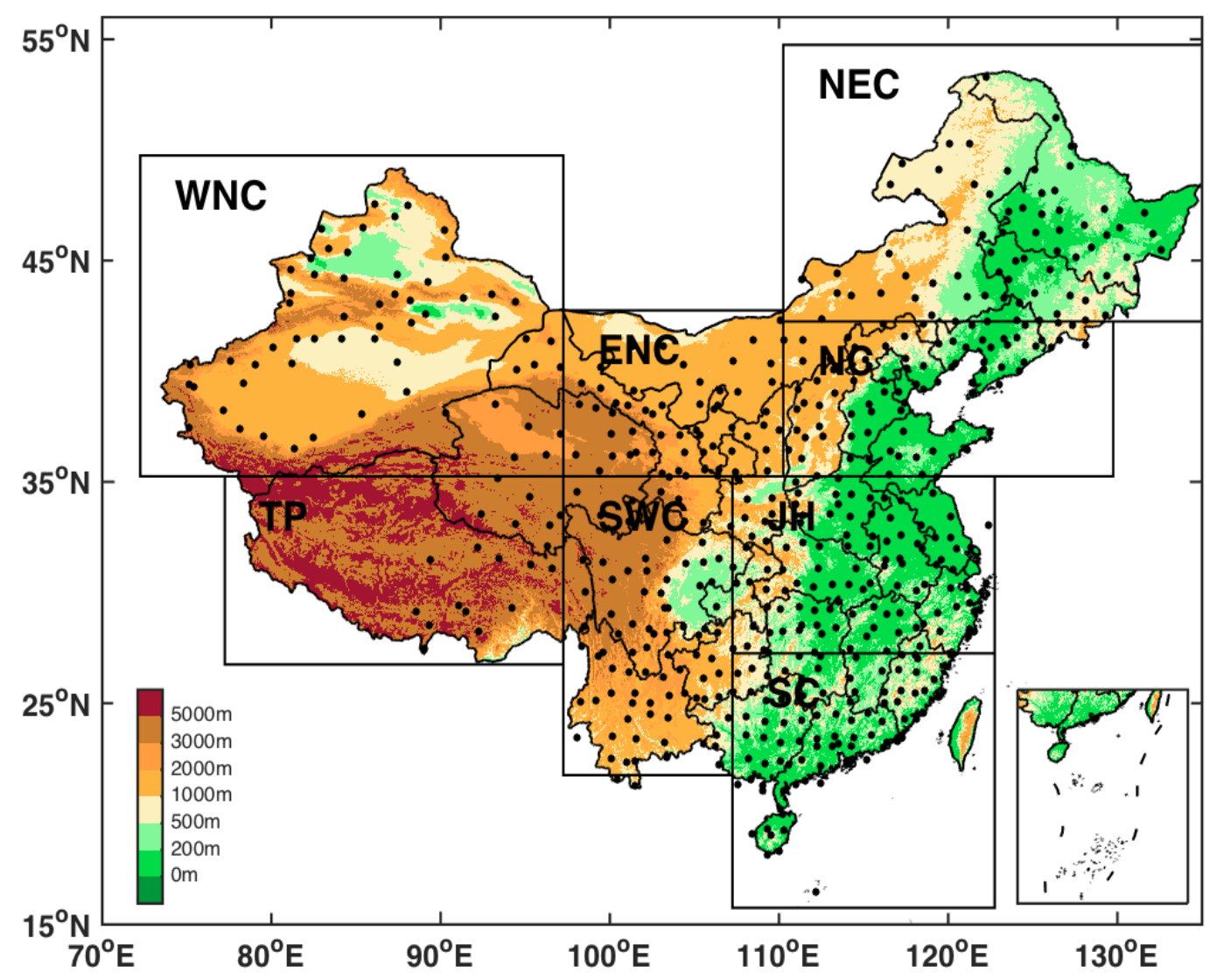

Figure 1. Distribution of stations used in this study, and the eight sub-regions in China. Dots denote the locations of observed stations. The lower right corner of the figure is the South China Sea islands. Eight sub-regions include Northeast China $\left(\mathrm{NEC}, 42.25{ }^{\circ} \mathrm{N}-54.75{ }^{\circ} \mathrm{N}, 110.25^{\circ} \mathrm{E}\right.$ $\left.-135.25^{\circ} \mathrm{E}\right)$, North China (NC, $\left.35.25^{\circ} \mathrm{N}-42.25^{\circ} \mathrm{N}, 110.25^{\circ} \mathrm{E}-129.75^{\circ} \mathrm{E}\right)$, Jianghuai $\left(\mathrm{JH}, 27.25^{\circ} \mathrm{N}\right.$ $\left.-35.25^{\circ} \mathrm{N}, 107.25^{\circ} \mathrm{E}-122.75^{\circ} \mathrm{E}\right)$, South China $\left(\mathrm{SC}, 15.75^{\circ} \mathrm{N}-27.25^{\circ} \mathrm{N}, 107.25^{\circ} \mathrm{E}-122.75^{\circ} \mathrm{E}\right)$, 

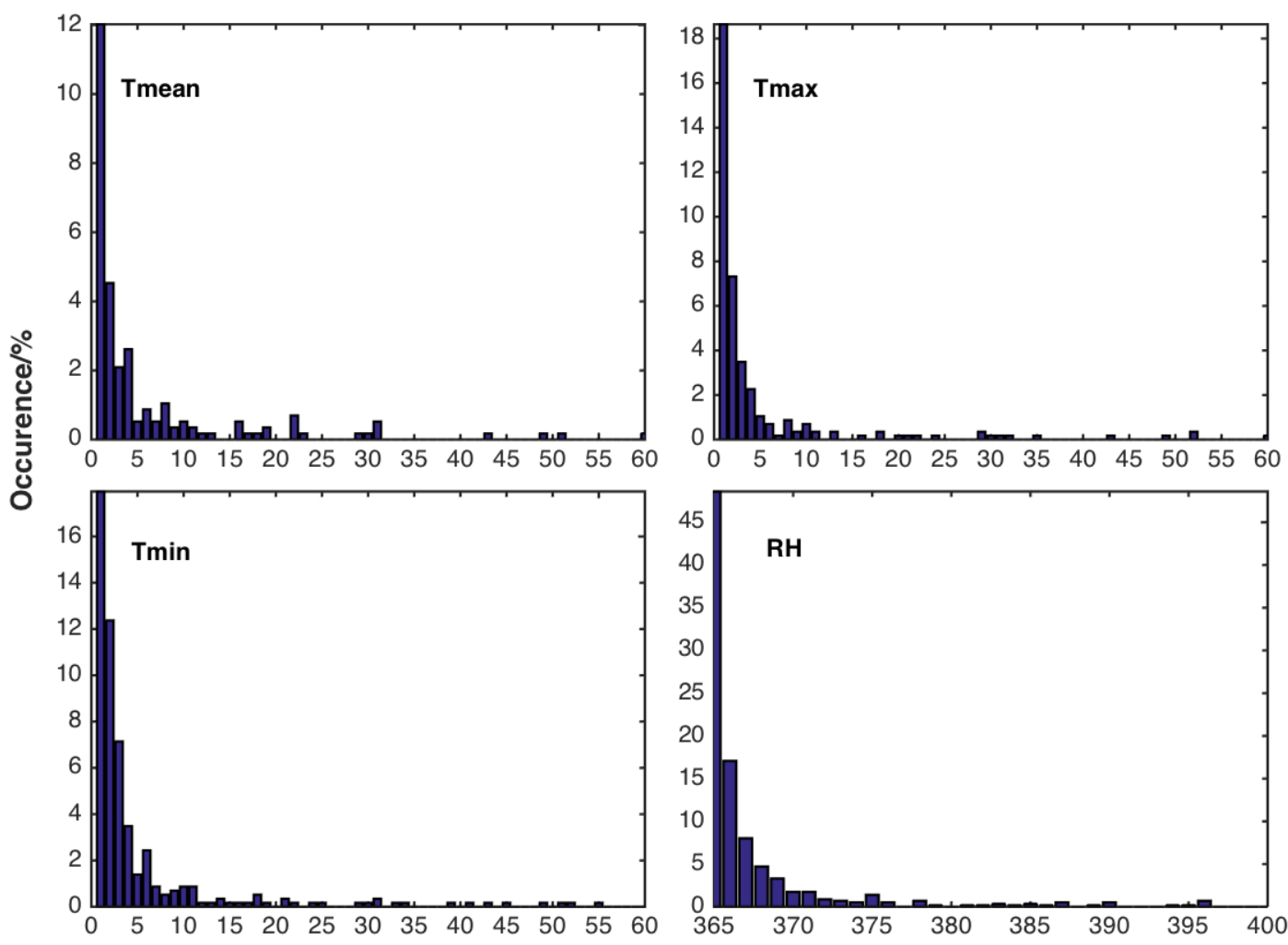

467 The number of missing days [days]

468 Figure 2. The distribution of the number of missing days of daily mean temperature (Tmean), maximum temperature (Tmax), minimum temperature (Tmin) and relative humidity $(\mathrm{RH})$ in the 654 station records. 

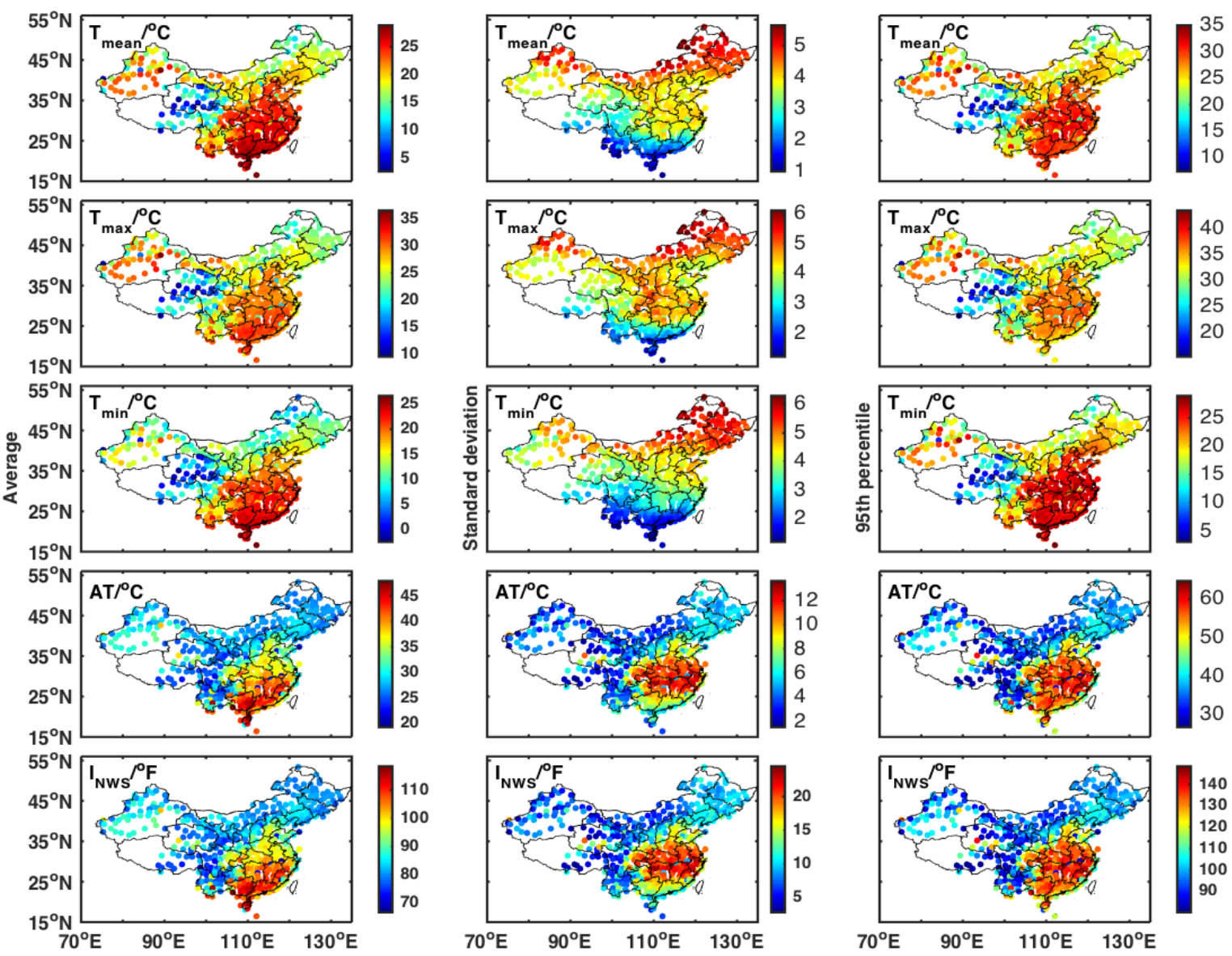

478 Figure 3. Average (left panel), standard deviation (middle panel) and 95th percentile (right panel) of five temperature metrics in China during 1961-1990: daily mean temperature (Tmean/ ${ }^{\circ} \mathrm{C}$ ), maximum temperature $\left(\operatorname{Tmax} /{ }^{\circ} \mathrm{C}\right)$, minimum temperature $\left(\operatorname{Tmin} /{ }^{\circ} \mathrm{C}\right)$, apparent temperature $\left(\mathrm{AT}^{\circ}{ }^{\circ} \mathrm{C}\right)$ and the National Weather Service's (NWS) heat index $\left(\mathrm{I}_{\mathrm{NWS}} /{ }^{\circ} \mathrm{F}\right)$. 

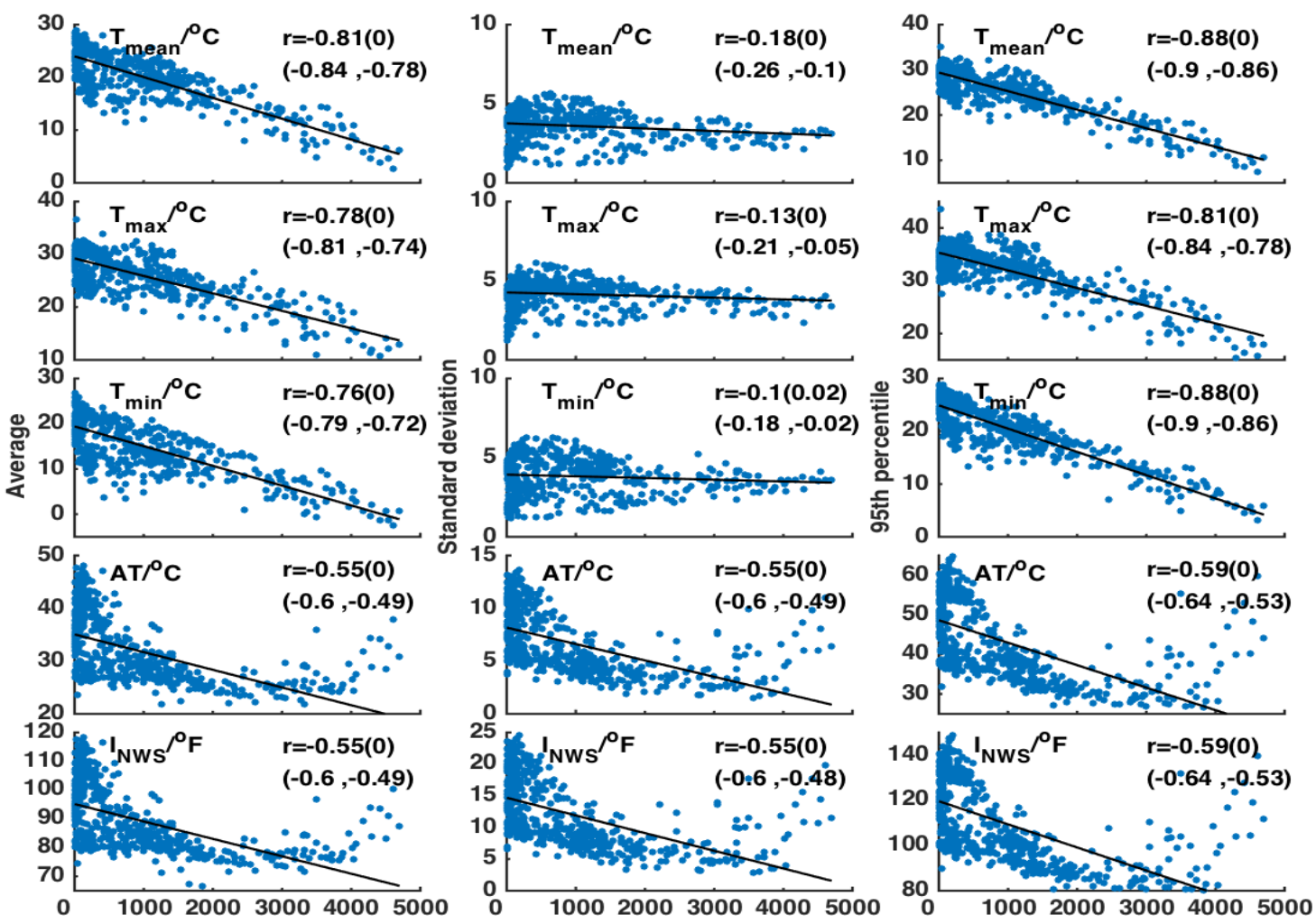

492 Figure 4. Correlation coefficients between average (left panel), standard deviation (middle panel)

493 and 95th percentile (right panel) of five temperature metrics in China during 1961-1990 and the

494 elevation $(\mathrm{m})$ of stations in China. Five temperature metrics are daily mean temperature

$495\left(\mathrm{Tmean} /{ }^{\circ} \mathrm{C}\right)$, maximum temperature $\left(\operatorname{Tmax} /{ }^{\circ} \mathrm{C}\right)$, minimum temperature $\left(\mathrm{Tmin} /{ }^{\circ} \mathrm{C}\right)$, apparent

496 temperature $\left(\mathrm{AT} /{ }^{\circ} \mathrm{C}\right)$ and the National Weather Service's (NWS) heat index (INWS/ $\left.{ }^{\circ} \mathrm{F}\right)$. Texts are correlation coefficients with its $\mathrm{P}$ values and $95 \%$ confidence interval (in parentheses). 

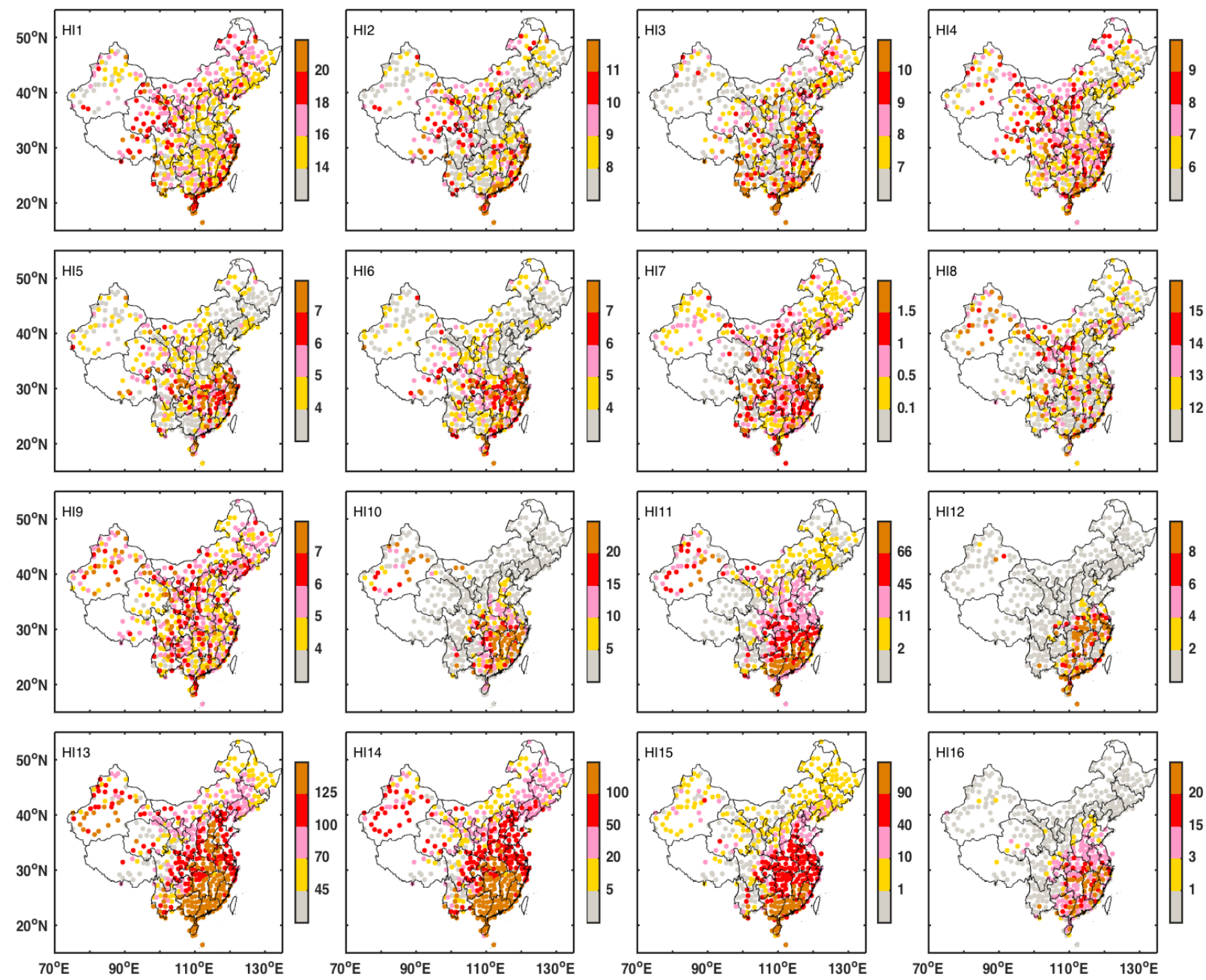

Figure 5. Average annual number of heat wave days in China during 1961-2014 according to the 

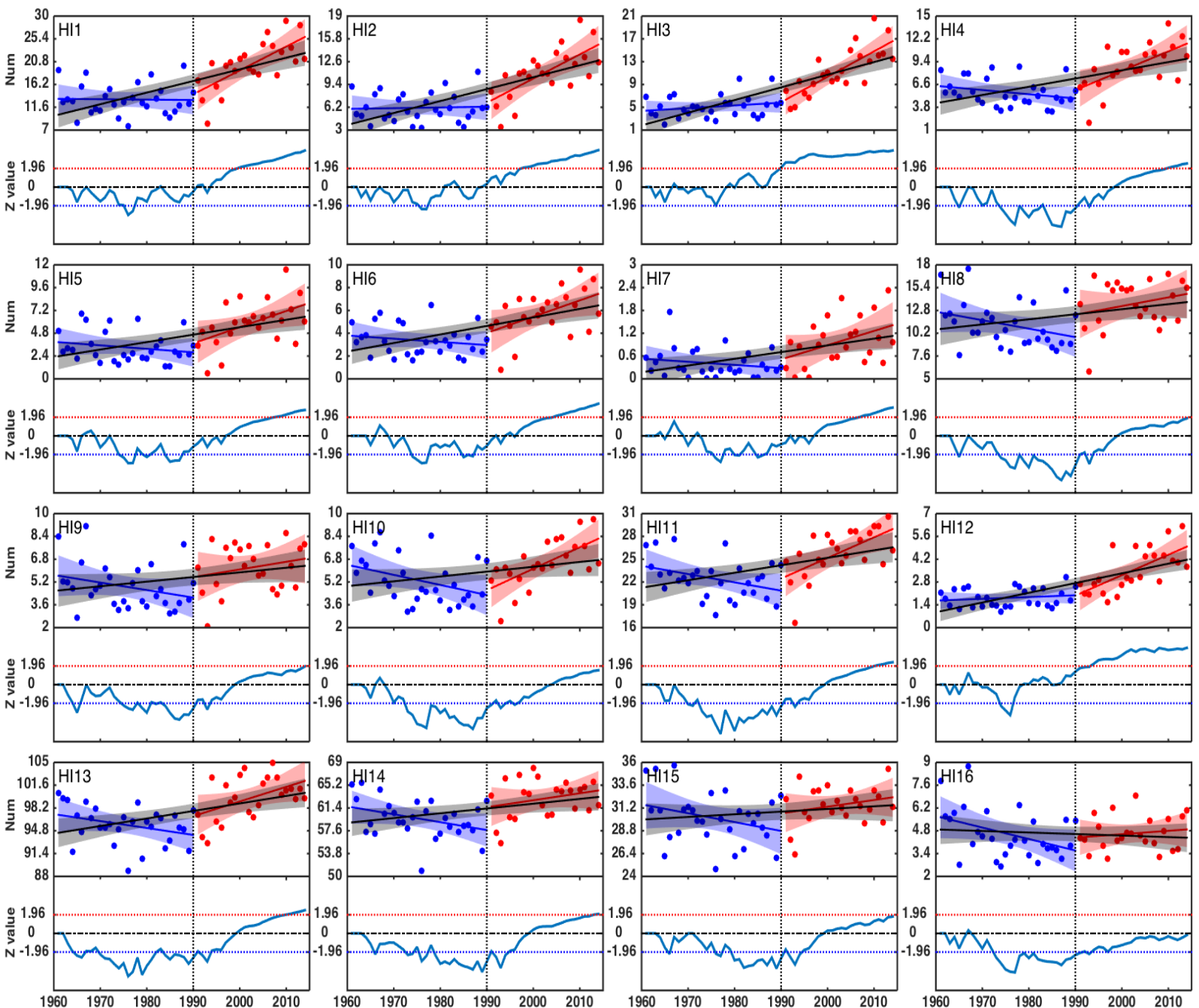

Figure 6. Time series of average annual heat wave frequency (upper panels) and $\mathrm{Z}$ values with

modified Mann-Kendall trend test (lower panel) over the whole of China during 1961-2014 for denotes GLM for 1991-2014, respectively. The shading represents the 95\% confidence level. 


\begin{tabular}{|c|c|c|c|c|c|c|c|c|c|c|c|c|c|c|c|c|c|c|c|c|c|c|c|c|}
\hline & \multicolumn{3}{|c|}{ NEC } & \multicolumn{3}{|c|}{ NC } & \multicolumn{3}{|c|}{ JH } & \multicolumn{3}{|c|}{ SC } & \multicolumn{3}{|c|}{ SWC } & \multicolumn{3}{|c|}{ TP } & \multicolumn{3}{|c|}{ WNC } & \multicolumn{3}{|c|}{ ENC } \\
\hline & 1961-2014 & 1961-1990 & 1991-2014 & |1961-2014 & |196-1990 & 1991-2014 & 1961-2014 & 1961-1990| & 1991-2014 & 1961-2014 & 1961-1990 & 1991-2014 & 1961-2014 & 1961-1990 & 1991-2014 & 1961-2014 & 1961-1990 & 1991-2014 & 1961-2014 & 1966-1990 & 1991-2014 & 1961-2014 & 1961-1990 & 1991-2014 \\
\hline HI1 & 2.77 & 1.53 & 5.84 & 2.14 & -2.71 & 5.25 & 2.45 & -3.95 & 5.74 & 4.14 & 4.57 & 8.74 & 3.28 & 0.15 & 7.96 & 4.73 & 3.22 & 9.88 & 2.68 & 1.74 & 6.89 & 2.91 & -1.24 & 6.67 \\
\hline HI2 & 1.65 & 1.54 & 4.07 & 1.34 & -1.42 & 3.35 & 1.76 & -2.26 & 4.94 & 2.67 & 2.43 & 6.64 & 2.02 & 0.28 & 5.44 & 2.97 & 1.99 & 7 & 1.8 & 0.92 & 5.22 & 1.95 & -0.8 & 4.64 \\
\hline$H \mid 3$ & 1.75 & 1.49 & 4.35 & 1.44 & -0.6 & 3.33 & 1.98 & -0.75 & 5.13 & 3.23 & 2.11 & 8.71 & 2.79 & 0.76 & 7.38 & 2.86 & 0.86 & 8 & 1.71 & 1.09 & 4.62 & 1.86 & -0.33 & 5.46 \\
\hline $\mathrm{H} / 4$ & 1.02 & -0.68 & 2.87 & 0.83 & -1.65 & 2.37 & 1.6 & -1.91 & 3.75 & 2.05 & 1.15 & 5.44 & 1.57 & -0.11 & 4.55 & 1.4 & 1.24 & 3.09 & 1.26 & 0.54 & 3.27 & 1.36 & -0.87 & 4.53 \\
\hline HI5 & $\mathrm{NaN}$ & $\mathrm{NaN}$ & 0.71 & $\mathrm{NaN}$ & NaN & 1.55 & 1.26 & $\mathrm{NaN}$ & 3.36 & 0.72 & -0.88 & 4.32 & 0.29 & NaN & 2.75 & 0.31 & $\mathrm{NaN}$ & 3.72 & 0.39 & $\mathrm{NaN}$ & 0.82 & 0.02 & $\mathrm{NaN}$ & 2.33 \\
\hline$H 16$ & $\mathrm{NaN}$ & $\mathrm{NaN}$ & 1.25 & $\mathrm{NaN}$ & NaN & $\mathrm{NaN}$ & 1.44 & -0.19 & 2.85 & 1.06 & -0.23 & 4.59 & 0.11 & -0.31 & 2.35 & 0.4 & $\mathrm{NaN}$ & 4.75 & 0.03 & 0.85 & 0.74 & 0.1 & $\mathrm{NaN}$ & 1.88 \\
\hline $\mathrm{HI}$ & $\mathrm{NaN}$ & $\mathrm{NaN}$ & $\mathrm{NaN}$ & $\mathrm{NaN}$ & NaN & $\mathrm{NaN}$ & $\mathrm{NaN}$ & $\mathrm{NaN}$ & 1 & $\mathrm{NaN}$ & NaN & NaN & $\mathrm{NaN}$ & NaN & $\mathrm{NaN}$ & $\mathrm{NaN}$ & $\mathrm{NaN}$ & $\mathrm{NaN}$ & $\mathrm{NaN}$ & $\mathrm{NaN}$ & $\mathrm{NaN}$ & $\mathrm{NaN}$ & $\mathrm{NaN}$ & $\mathrm{NaN}$ \\
\hline HII8 & 0.95 & -0.97 & 4.02 & 0.48 & -2.32 & -1.44 & -0.41 & -3.17 & 0.63 & 1.24 & -0.57 & 2.28 & 1.31 & -0.84 & 5.6 & -0.2 & -0.02 & 4.49 & 1.95 & 0.86 & -3.2 & 1.05 & -1.31 & 0.44 \\
\hline HII & 0.26 & 0.82 & 1.55 & 0.52 & -1.48 & 0.64 & -0.13 & -1.71 & 0.33 & 0.72 & -0.66 & 1.57 & 0.66 & -0.7 & 3.21 & -0.17 & -0.84 & 2.1 & 1.14 & 0.67 & -2.11 & 0.64 & -0.42 & -0.56 \\
\hline HH10 & $\mathrm{NaN}$ & $\mathrm{NaN}$ & $\mathrm{NaN}$ & -1.67 & -2.03 & 1.75 & 1.28 & -3.53 & 5 & 2.03 & -0.92 & 6.06 & 1.14 & -1.31 & 6.54 & $\mathrm{NaN}$ & $\mathrm{NaN}$ & NaN & 1.75 & 1.07 & 3.41 & 0.84 & -1.42 & $\mathrm{NaN}$ \\
\hline Hl11 & 0.78 & -0.4 & 1.7 & 1.03 & -3.6 & 0.93 & 1.06 & -5.96 & 7.62 & 4.69 & 4.74 & 8.47 & 1.92 & -4.46 & 7.05 & $\mathrm{NaN}$ & $\mathrm{NaN}$ & NaN & 2.72 & -1.2 & 6.58 & 1.36 & -2.27 & 5.3 \\
\hline HI12 & $\mathrm{NaN}$ & $\mathrm{NaN}$ & $\mathrm{NaN}$ & $\mathrm{NaN}$ & NaN & $\mathrm{NaN}$ & 1.67 & -1.18 & 4.56 & 2.7 & 2.24 & 7.37 & 0.75 & -0.68 & 3.27 & NaN & $\mathrm{NaN}$ & NaN & 0.28 & $\mathrm{NaN}$ & 2.89 & $\mathrm{NaN}$ & $\mathrm{NaN}$ & $\mathrm{NaN}$ \\
\hline HI13 & 2.28 & -3.58 & 5.64 & 1.74 & -3.58 & 2.18 & 1.77 & -2.96 & 3.47 & 0.79 & -1.48 & 3.29 & 2.53 & -1.44 & 7.43 & $\cdot 0.54$ & 1.35 & 0.65 & 1.55 & 0.12 & 2.44 & 1.41 & -2.89 & 2.85 \\
\hline HI14 & 1.66 & -2.64 & 4.83 & 1.69 & -3.27 & 1.75 & 1.34 & -3.47 & 3.51 & 0.58 & -2.4 & 1.72 & 1.51 & -1.04 & 5.13 & -1.44 & -0.24 & -1.34 & 2.91 & 1.33 & -2.8 & 0.86 & -2.47 & -0.51 \\
\hline HI15 & -0.15 & -0.01 & 0.27 & 0.04 & -2.57 & -2.71 & 0.04 & -4.35 & 3.35 & 2.19 & 0.38 & 4.58 & 0.96 & -2.66 & 3.54 & -1.6 & -0.59 & -4.85 & 1.02 & 1.23 & -1.93 & -0.07 & -0.68 & -1 \\
\hline HI16 & $\mathrm{NaN}$ & $\mathrm{NaN}$ & NaN & -0.4 & -1.17 & -0.17 & -0.96 & -3.28 & 0.23 & $\cdot 0.2$ & -1.83 & 1.36 & 0.02 & -0.9 & 2.17 & -0.37 & 0.5 & 2 & \begin{tabular}{|l|l}
-0.56 \\
\end{tabular} & -2.22 & -1.1 & $\mathrm{NaN}$ & $\mathrm{NaN}$ & -0.71 \\
\hline
\end{tabular}

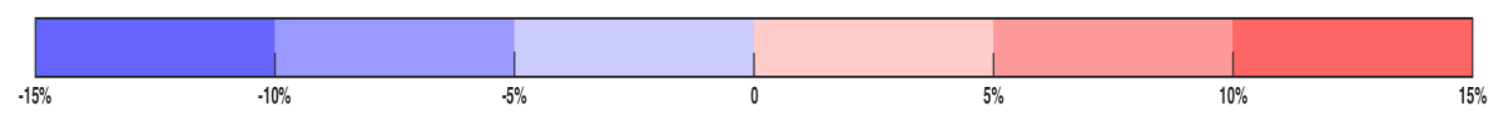

537 Figure 7. Trends (days/decade) in the number of annual heat wave days over eight sub-regions in

538 China for each heat wave index (HI) during the periods 1961-2014, 1961-1990 and 1991-2014,

539 respectively. NaN means the trends failing the significant test. The color of the cell represents

540 positive (red) and negative (blue) trends. The shades of red/blue represent the station percentage

541 covered by this significant trend given by the scale bar. 

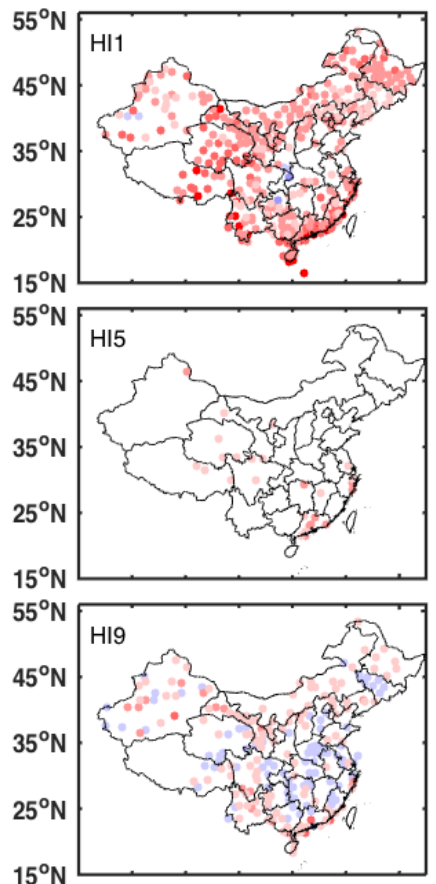

$15^{\circ} \mathrm{N}$

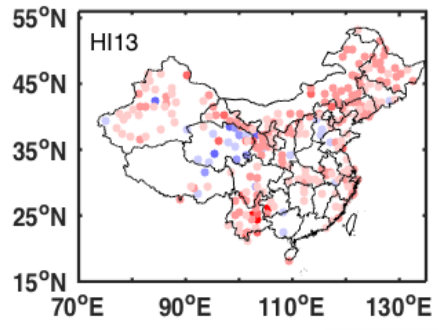

sub-regions in China during 1961-2014 for each heat wave index (HI).
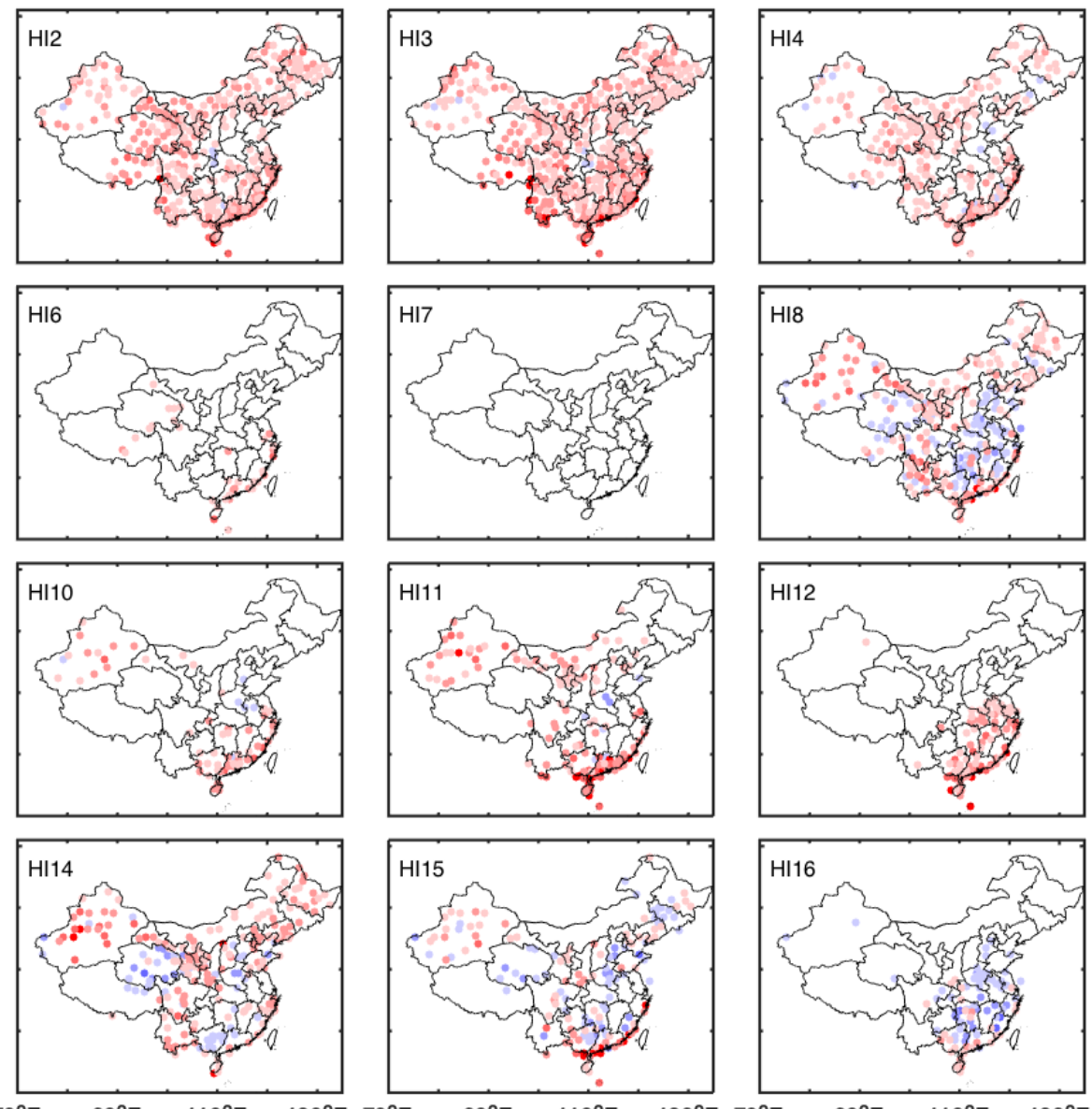

$-6$

Figure 8. Spatial distribution of trends in the number of annual heat wave days over eight 

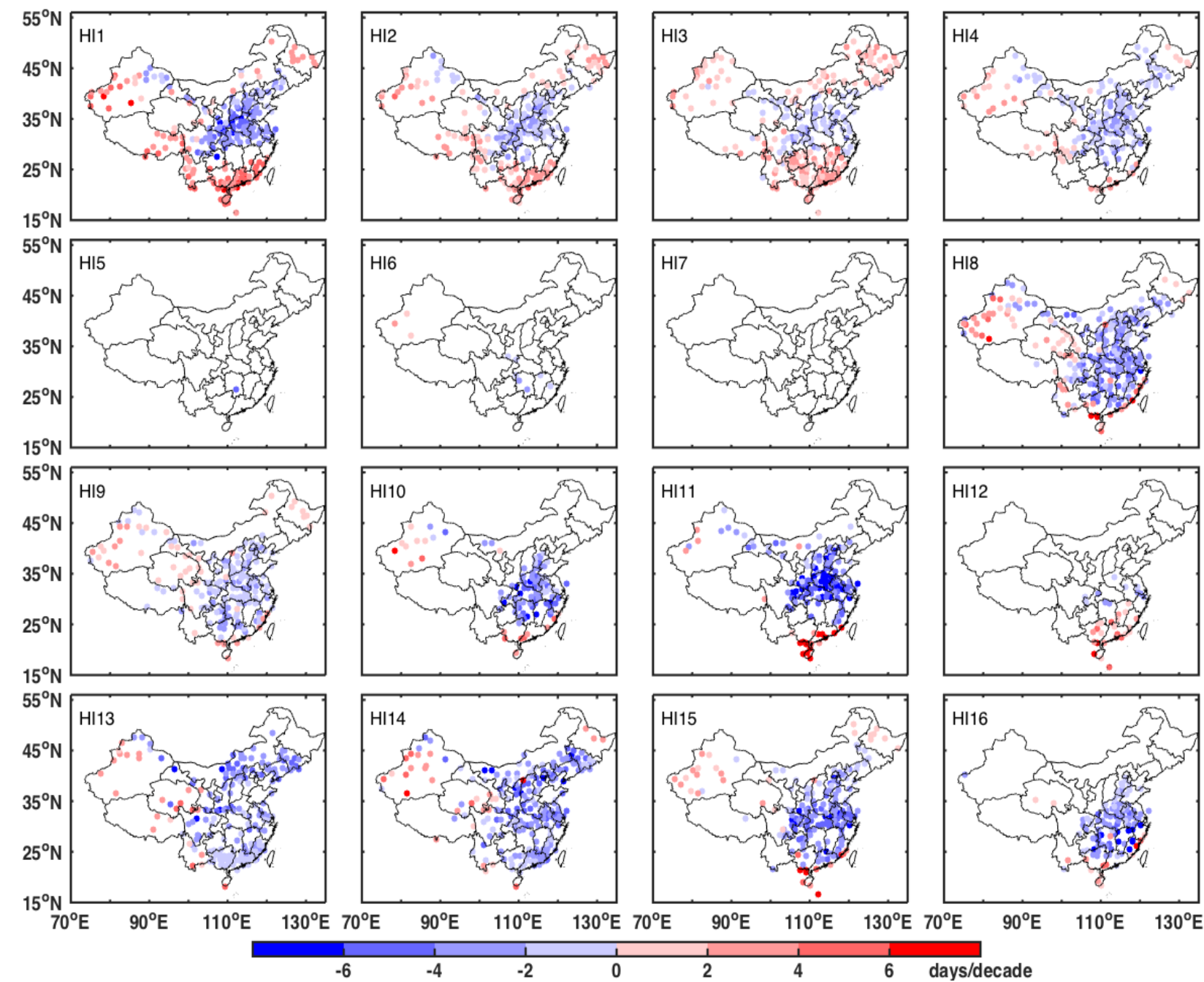

567 Figure 9. Same as Figure 8 but for the period 1961-1990. 

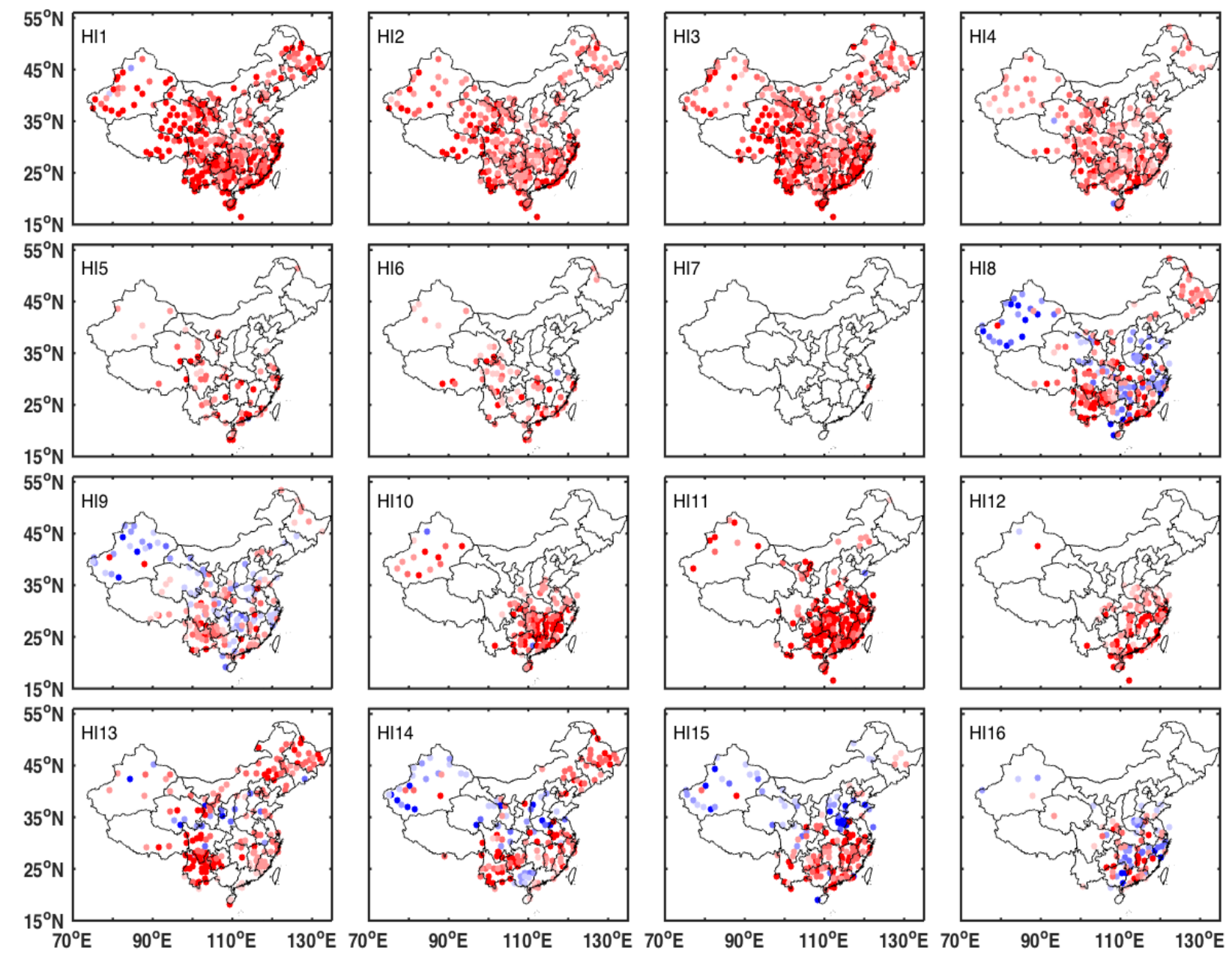

Figure 10. Same as Figure 8 but for the period 1991-2014. 
592 Tables

593 Table 1. Definitions of heat wave indices (HI) including temperature metric, threshold, duration

594 and HI type. 12 HIs follow the methods of (Smith et al., 2013). Temperature metrics are daily

595 mean temperature (Tmean), daily maximum temperature (Tmax), daily minimum temperature

596 (Tmin), daily maximum apparent temperature (ATmax) and daily maximum heat index (HImax).

\begin{tabular}{|c|c|c|c|c|c|}
\hline $\begin{array}{l}\text { Heat wave } \\
\text { Indices }(\mathrm{HI})\end{array}$ & $\begin{array}{l}\text { Temperature } \\
\text { Metric }\end{array}$ & Threshold & Duration & Reference & $\begin{array}{l}\mathrm{HI} \\
\text { type }\end{array}$ \\
\hline HI1 & Tmean & $>90$ th percentile & $2+$ consecutive days & (Anderson and Bell, 2011) & \multirow{9}{*}{ 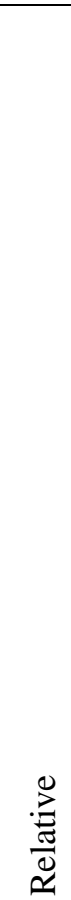 } \\
\hline HI2 & Tmean & $>95$ th percentile & $2+$ consecutive days & (Anderson and Bell, 2011) & \\
\hline HI3 & Tmin & $>95$ th percentile & $2+$ consecutive days & (Anderson and Bell, 2011) & \\
\hline HI 4 & Tmax & $>95$ th percentile & $2+$ consecutive days & (Anderson and Bell, 2011) & \\
\hline HI5 & Tmax & $\begin{array}{l}\text { T1: >81st percentile } \\
\mathrm{T} 2: \quad>97.5 \text { th } \\
\text { percentile }\end{array}$ & $\begin{array}{l}\text { Everyday, }>\mathrm{T} 1 ; \\
3+\text { consecutive days, }>\mathrm{T} 2 ; \\
\text { Avg Tmax }>\mathrm{T} 1 \text { for whole } \\
\text { time period }\end{array}$ & $\begin{array}{l}\text { (Meehl and Tebaldi, 2004; } \\
\text { Peng et al., 2011) }\end{array}$ & \\
\hline HI6 & Tmax & $>90$ th percentile & $6+$ consecutive days & (Fischer and Schär, 2010) & \\
\hline HI7 & Tmax & $\begin{array}{l}>97.5 \text { th percentile } \\
97.5 \text { th } \\
\text { percentile }>=29^{\circ} \mathrm{C}\end{array}$ & $6+$ consecutive days & (Ye et al., 2013) & \\
\hline HI8 & ATmax & $>90$ th percentile & 1 day & (Steadman, 1984) & \\
\hline HI9 & ATmax & $>95$ th percentile & 1 day & (Steadman, 1984) & \\
\hline HI10 & Tmax & $>35^{\circ} \mathrm{C}$ & $3+$ consecutive days & $\begin{array}{l}\text { (Chen et al., 2013; Tan } \\
\text { and Huang, 2004) }\end{array}$ & \multirow{7}{*}{ ప } \\
\hline HI11 & Tmax & $>32{ }^{\circ} \mathrm{C}$ & $3+$ consecutive days & $\begin{array}{l}\text { (Chen et al., 2013; Tan } \\
\text { and Huang, 2004) }\end{array}$ & \\
\hline HI12 & $\begin{array}{l}\text { Tmax and } \\
\text { Tmin }\end{array}$ & $\begin{array}{l}\operatorname{Tmin}>26.7 \quad{ }^{\circ} \mathrm{C} ; \\
\operatorname{Tmax}>40.6{ }^{\circ} \mathrm{C}\end{array}$ & $\begin{array}{l}\geq 1 \text { threshold; } \\
2+\text { consecutive days }\end{array}$ & (Robinson, 2001) & \\
\hline HI13 & HImax & $>80^{\circ} \mathrm{F}$ & 1 day & (Steadman, 1979) & \\
\hline HI14 & HImax & $>90^{\circ} \mathrm{F}$ & 1 day & (Steadman, 1979) & \\
\hline HI15 & HImax & $>105^{\circ} \mathrm{F}$ & 1 day & (Steadman, 1979) & \\
\hline HI16 & HImax & $>130^{\circ} \mathrm{F}$ & 1 day & (Steadman, 1979) & \\
\hline
\end{tabular}


Table 2. Average number of annual heat wave days over eight sub-regions in China during

598 1961-2014 for each heat wave index (HI). Values in bold indicate the sub-region with the highest

599 frequency of heat waves days for each HI.

\begin{tabular}{llllllllll}
\hline & NEC & NC & JH & SC & SWC & TP & WNC & ENC & Entire China \\
\hline HI1 & 16.41 & 15.55 & 15.70 & 18.00 & 15.86 & $\mathbf{1 8 . 9 4}$ & 15.45 & 16.75 & 16.58 \\
\hline HI2 & 8.09 & 7.62 & 8.17 & 9.60 & 8.07 & $\mathbf{1 0 . 1 3}$ & 7.57 & 8.64 & 8.49 \\
\hline HI3 & 7.73 & 7.35 & 8.07 & $\mathbf{9 . 5 9}$ & 8.33 & 8.47 & 6.04 & 7.32 & 7.86 \\
\hline HI4 & 6.40 & 6.33 & 7.16 & $\mathbf{7 . 8 0}$ & 7.22 & 7.66 & 7.03 & 7.37 & 7.12 \\
\hline HI5 & 3.58 & 3.49 & $\mathbf{5 . 5 1}$ & 4.76 & 4.48 & 5.25 & 4.22 & 4.29 & 4.45 \\
\hline HI6 & 3.31 & 3.18 & $\mathbf{5 . 8 6}$ & 5.37 & 4.38 & 5.35 & 3.75 & 4.00 & 4.40 \\
\hline HI7 & 0.39 & 0.46 & $\mathbf{1 . 1 0}$ & 0.82 & 0.66 & 0.07 & 0.39 & 0.62 & 0.56 \\
\hline HI8 & 11.91 & 12.19 & 12.23 & 12.20 & 11.82 & 11.01 & $\mathbf{1 3 . 3 6}$ & 12.47 & 12.15 \\
\hline HI9 & 5.14 & 5.47 & 5.43 & 5.48 & 5.33 & 4.86 & $\mathbf{6 . 2 7}$ & 5.56 & 5.44 \\
\hline HI10 & 0.31 & 1.48 & $\mathbf{1 2 . 3 7}$ & 10.49 & 2.87 & 0.00 & 9.40 & 1.45 & 4.80 \\
\hline HI11 & 2.94 & 10.29 & 39.42 & $\mathbf{5 6 . 7 2}$ & 12.42 & 0.00 & 28.73 & 8.44 & 19.87 \\
\hline HI12 & 0.00 & 0.20 & 5.82 & $\mathbf{8 . 1 5}$ & 0.52 & 0.00 & 0.95 & 0.03 & 1.96 \\
\hline HI13 & 71.06 & 91.56 & 118.43 & $\mathbf{1 3 8 . 9 4}$ & 83.14 & 55.28 & 90.65 & 73.81 & 90.35 \\
\hline HI14 & 25.64 & 47.88 & 91.77 & $\mathbf{1 2 4 . 6 1}$ & 46.67 & 22.81 & 37.13 & 22.30 & 52.35 \\
\hline HI15 & 3.80 & 13.85 & 55.01 & $\mathbf{8 8 . 4 8}$ & 18.60 & 7.77 & 5.53 & 1.98 & 24.38 \\
\hline HI16 & 0.08 & 0.77 & 11.69 & $\mathbf{1 1 . 8 8}$ & 2.11 & 1.27 & 5.40 & 0.09 & 3.52 \\
\hline
\end{tabular}

600

601

602

603

604

605

606

607

608

609

610

611

612

613

614

615

616

617

618

619 
Table 3. Correlation coefficients between average numbers of annual heat wave days for each

621 heat wave index (HI)

\begin{tabular}{|c|c|c|c|c|c|c|c|c|c|c|c|c|c|c|c|c|}
\hline & HI1 & HI2 & HI3 & HI4 & HI5 & HI6 & HI7 & HI8 & HI9 & HI10 & HI11 & HI12 & HI13 & HI14 & HI15 & HI16 \\
\hline HI1 & 1.00 & & & & & & & & & & & & & & & \\
\hline HI2 & 0.93 & 1.00 & & & & & & & & & & & & & & \\
\hline HI3 & 0.60 & 0.61 & 1.00 & & & & & & & & & & & & & \\
\hline HI4 & 0.50 & 0.56 & 0.27 & 1.00 & & & & & & & & & & & & \\
\hline HI5 & 0.35 & 0.46 & 0.24 & 0.76 & 1.00 & & & & & & & & & & & \\
\hline HI6 & 0.41 & 0.50 & 0.31 & 0.73 & 0.88 & 1.00 & & & & & & & & & & \\
\hline HI7 & 0.16 & 0.27 & 0.21 & 0.52 & 0.68 & 0.67 & 1.00 & & & & & & & & & \\
\hline HI8 & 0.09 & 0.05 & -0.09 & 0.42 & 0.20 & 0.18 & 0.21 & 1.00 & & & & & & & & \\
\hline HI9 & 0.12 & 0.08 & -0.09 & 0.45 & 0.25 & 0.22 & 0.20 & 0.94 & 1.00 & & & & & & & \\
\hline HI10 & -0.15 & -0.08 & -0.07 & 0.02 & 0.24 & 0.25 & 0.25 & -0.08 & -0.06 & 1.00 & & & & & & \\
\hline HI11 & -0.07 & 0.00 & 0.04 & 0.08 & 0.20 & 0.27 & 0.29 & -0.06 & -0.05 & 0.82 & 1.00 & & & & & \\
\hline HI12 & 0.26 & 0.29 & 0.26 & 0.16 & 0.26 & 0.35 & 0.27 & -0.06 & -0.06 & 0.32 & 0.37 & 1.00 & & & & \\
\hline HI13 & 0.00 & 0.05 & 0.13 & 0.06 & 0.16 & 0.24 & 0.35 & 0.05 & 0.05 & 0.55 & 0.77 & 0.39 & 1.00 & & & \\
\hline HI14 & 0.05 & 0.11 & 0.21 & 0.10 & 0.21 & 0.33 & 0.35 & -0.05 & -0.05 & 0.58 & 0.84 & 0.47 & 0.93 & 1.00 & & \\
\hline HI15 & 0.09 & 0.17 & 0.24 & 0.14 & 0.25 & 0.39 & 0.35 & -0.14 & -0.13 & 0.58 & 0.85 & 0.48 & 0.78 & 0.94 & 1.00 & \\
\hline HI16 & -0.05 & 0.04 & 0.10 & 0.09 & 0.30 & 0.39 & 0.36 & -0.19 & -0.17 & 0.70 & 0.76 & 0.24 & 0.57 & 0.69 & 0.80 & 1.00 \\
\hline \multicolumn{17}{|c|}{622} \\
\hline \multicolumn{17}{|c|}{623} \\
\hline \multicolumn{17}{|c|}{624} \\
\hline \multicolumn{17}{|c|}{625} \\
\hline \multicolumn{17}{|c|}{626} \\
\hline \multicolumn{17}{|c|}{627} \\
\hline \multicolumn{17}{|c|}{628} \\
\hline \multicolumn{17}{|c|}{629} \\
\hline \multicolumn{17}{|c|}{630} \\
\hline \multicolumn{17}{|c|}{631} \\
\hline \multicolumn{17}{|c|}{632} \\
\hline \multicolumn{17}{|c|}{633} \\
\hline \multicolumn{17}{|c|}{634} \\
\hline \multicolumn{17}{|c|}{635} \\
\hline \multicolumn{17}{|c|}{636} \\
\hline \multicolumn{17}{|c|}{637} \\
\hline \multicolumn{17}{|c|}{638} \\
\hline \multicolumn{17}{|c|}{639} \\
\hline \multicolumn{17}{|c|}{640} \\
\hline \multicolumn{17}{|c|}{641} \\
\hline \multicolumn{17}{|c|}{642} \\
\hline & 43 & & & & & & & & & & & & & & & \\
\hline & 44 & & & & & & & & & & & & & & & \\
\hline
\end{tabular}


Table 4. Summary of past studies of trends and patterns of heat waves on regional and worldwide

scales. The definition of the heat wave is given in full if not one of the sixteen used in this study.

\begin{tabular}{|c|c|c|c|c|}
\hline Continent & Region/country & Heat wave index & Study period & Reference \\
\hline \multirow{8}{*}{ Europe } & Ukraine & $\begin{array}{l}\text { a period of more than } 5 \\
\text { consecutive days with } \text { Tmax } \geq 5 \\
{ }^{\circ} \mathrm{C} \text { above the mean Tmax for the } \\
\text { normal climatic } \\
\text { 1961-1990 }\end{array}$ & $1951-2011$ & $\begin{array}{l}\text { (Shevchenko et } \\
\text { al., 2014) }\end{array}$ \\
\hline & Hungary & Tmean $\geq 25^{\circ} \mathrm{C}, 1$ consecutive day & $1961-2100$ & $\begin{array}{l}\text { (Pongrácz et al., } \\
\text { 2013) }\end{array}$ \\
\hline & Turkey & HI9 & $1965-2006$ & $\begin{array}{l}\text { (Unal et al., } \\
2013)\end{array}$ \\
\hline & Entire Europe & HI6 & $1961-2100$ & $\begin{array}{l}\text { (Fischer and } \\
\text { Schär, 2010) }\end{array}$ \\
\hline & Western Europe & $\begin{array}{l}\text { the number of consecutive } 3 \text {-day } \\
\text { periods that exceed the long-term } \\
\text { daily } 80 \text { th percentile of Tmax }\end{array}$ & $1880-2003$ & $\begin{array}{l}\text { (Della-Marta et } \\
\text { al., 2007) }\end{array}$ \\
\hline & Czech Republic & HI5 & $1961-2100$ & (Kyselý, 2010) \\
\hline & Central Europe & $\begin{array}{l}\text { Tmax above the 95th annual } \\
\text { percentile }\end{array}$ & & $\begin{array}{l}\text { (Tomczyk and } \\
\text { Bednorz, 2016) }\end{array}$ \\
\hline & Western Europe & $\begin{array}{l}\text { periods of } \\
\text { at least } 3 \text { consecutive days of } \\
\text { extremely high daily maximum } \\
\text { temperature affecting at least } \\
30 \% \text { of western Europe }\end{array}$ & $1979-2100$ & $\begin{array}{l}\text { (Schoetter et al., } \\
2015)\end{array}$ \\
\hline \multirow[t]{4}{*}{ America } & Continental U.S. & Multiple HI & $1979-2011$ & $\begin{array}{l}\text { (Smith et al., } \\
\text { 2013) }\end{array}$ \\
\hline & $\begin{array}{l}\text { Pacific } \\
\text { Northwest }\end{array}$ & $\begin{array}{l}3 \text { or more consecutive days above } \\
\text { the 99th percentile for the } \\
\text { maximum }\left(9.5^{\circ} \mathrm{C}\right) \text { or minimum } \\
\left(4.6^{\circ} \mathrm{C}\right) \text { temperature anomalies }\end{array}$ & $1901-2009$ & $\begin{array}{l}\text { (Bumbaco et al., } \\
\text { 2013) }\end{array}$ \\
\hline & $\begin{array}{l}\text { North } \\
\text { America }\end{array}$ & HI6 & $1958-2010$ & $\begin{array}{l}\left(\begin{array}{l}Z \\
\text { 2012b) }\end{array}\right. \\
\text { et al., }\end{array}$ \\
\hline & $\begin{array}{l}50 \text { large US } \\
\text { cities }\end{array}$ & $\begin{array}{l}\text { Similar to HI08, but for } 85^{\text {th }} \\
\text { percentile }\end{array}$ & $1961-2010$ & $\begin{array}{l}\text { (Habeeb et al., } \\
\text { 2015) }\end{array}$ \\
\hline \multirow[t]{4}{*}{ Asia } & China & HI6 & 1968-2009 & $\begin{array}{l}\left(\begin{array}{l}Z \\
\text { 2012a }\end{array}\right) \\
\text { et al., }\end{array}$ \\
\hline & China & HI7 & 1961-2010 & (Ye et al., 2013) \\
\hline & China & $\begin{array}{l}\text { Similar to HI4, but for one } \\
\text { consecutive day }\end{array}$ & $1960-2005$ & $\begin{array}{ll}\text { (Wang et al., } \\
2015)\end{array}$ \\
\hline & Shanghai & $\mathrm{HI} 7$ & $1873-2010$ & (Chen et al., \\
\hline
\end{tabular}




\begin{tabular}{|c|c|c|c|c|}
\hline & & & & 2013) \\
\hline & Japan & HI6 & $\begin{array}{l}1979-2003 \text { and } \\
2075-2099\end{array}$ & $\begin{array}{l}\text { (Nakano et al., } \\
2013 \text { ) }\end{array}$ \\
\hline \multirow[t]{3}{*}{ Australia } & Entire Australia & $\begin{array}{l}\text { Tmax exceeds a 90th percentile } \\
\text { for three or more consecutive } \\
\text { days, and Tmin exceeds a 90th } \\
\text { percentile on the second and third } \\
\text { days }\end{array}$ & $2006-2100$ & $\begin{array}{l}\text { (Cowan et al., } \\
2014)\end{array}$ \\
\hline & $\begin{array}{l}\text { Southern } \\
\text { Australia }\end{array}$ & $\begin{array}{l}\text { Tmax exceeds a 90th percentile } \\
\text { for three or more consecutive } \\
\text { days, and Tmin exceeds a 90th } \\
\text { percentile on the second and third } \\
\text { days }\end{array}$ & $1979-2008$ & $\begin{array}{l}\text { (Pezza et al., } \\
2012)\end{array}$ \\
\hline & Australia & $\begin{array}{l}3 \text { or more consecutive days above } \\
\text { one of the following: the 90th } \\
\text { percentile for Tmax, the 90th } \\
\text { percentile for Tmin, and positive } \\
\text { extreme heat factor conditions. }\end{array}$ & $1951-2008$ & $\begin{array}{l}\text { (Perkins and } \\
\text { Alexander, 2013) }\end{array}$ \\
\hline Africa & Southern Africa & $\begin{array}{l}\text { daily Tmax values exceeded the } \\
\text { 90th percentile for at least } 3 \\
\text { consecutive days }\end{array}$ & $1961-2100$ & (Lyon, 2009) \\
\hline
\end{tabular}

647

648

649

650

651

652

653

654

655

656

657

658

659

660

661

662

663

664

665

666

667

668

669 
670 Table 5. Correlation coefficients between Pacific Decadal Oscillation (PDO) index and

$671 \quad 16$ heat wave indices during 1961-2014.

672

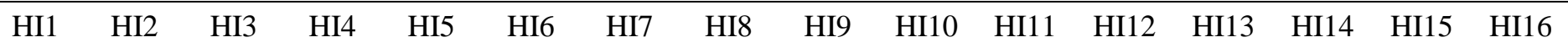

Before

detrend

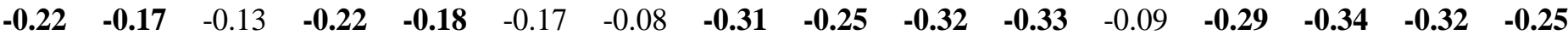

After

detrend

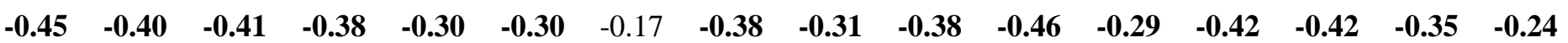

673 